\title{
CONSTRUCTAL DESIGN OF FINS IN COOLED CAVITIES BY NON-NEWTONIAN FLUIDS
}

\author{
J. F. Bueno, \\ A. R. S. Silva, \\ ABSTRACT \\ T. A. Hirt, \\ The present work investigates the Construtal Design of fins inserted in \\ cavities submitted to mixed convection by non-Newtonian fluids. The \\ objective is to obtain the optimum aspect ratio for the fin considering \\ different flow conditions and variations in the rheological parameters of the \\ fluid. The phenomena of flow and heat transfer are modeled by mass \\ balance, momentum and energy equations, and by the generalized \\ Newtonian liquid constitutive equation. The viscosity is modeled as that of \\ a pseudoplastic fluid, using the Carreau function. The optimization problem \\ consists in maximizing heat transfer from the fin using the average Nusselt \\ number. The investigated project variable is the aspect ratio between the \\ edges of the rectangular plane fin profile. The restrictions are the volume of \\ the cavity and the fin. The results are obtained numerically using a finite \\ volume code and a two-dimensional geometry, through exhaustive \\ searching. The results show that the fin geometry influences the maximum \\ Nusselt number mainly for the cases with high Reynolds and Rayleigh \\ numbers, such as was shown in previous studies. The results show that the \\ fin geometry influences the maximum Nusselt number mainly for the cases \\ with high Reynolds and Rayleigh numbers, as was shown in previous \\ studies. It was also found that the Nusselt number increases as the increase \\ in flow intensity, represented by the parameter $\mathrm{p}$, and that the result of the \\ maximum Nusselt number does not change monotonically with the non- \\ Newtonian dimensionless viscosity and with the flow index, showing that \\ the pseudoplasticity of the fluid implies optimal configurations very \\ different from those predicted for Newtonian fluids. \\ gcbogo@edu.unisinos.b \\ fzinani@unisinos.br \\ luizor@unisinos.br \\ Received: February 28, 2019 \\ Revised: March 20, 2019 \\ Accepted: April 15, 2019 \\ Keywords: fins; mixed convection; non-Newtonian fluids; computational \\ fluid dynamics; Constructal Design

\section{NOMENCLATURE} \\ a dimensionless parameter of the transition \\ region between the low shear rate region \\ and viscosity \\ $\mathrm{D}_{\mathrm{ij}} \quad$ strain rate tensor, $\mathrm{s}^{-1}$ \\ g gravity acceleration, $\mathrm{m} / \mathrm{s}^{2}$ \\ GCI grid convergence index \\ $\mathrm{H}, \mathrm{L} \quad$ height and width of the cavity, $\mathrm{m}$ \\ $\mathrm{H}_{1}, \mathrm{~L}_{1}$ height and width of the fin, $\mathrm{m}$ \\ $\mathrm{k}$ fluid thermal conductivity, $\mathrm{W} /(\mathrm{m} . \mathrm{K})$ \\ n power index \\ $\mathrm{Nu} \quad$ Nusselt number \\ Pr Prandtl number \\ q heat transfer rate from the fin, $\mathrm{W}$ \\ Ra Rayleigh number \\ Re Reynolds number \\ $\mathrm{T}_{\mathrm{W}} \quad$ prescribed temperature in the cavity walls, $\mathrm{K}$ \\ $\mathrm{T}_{\infty} \quad$ free stream fluid temperature, $\mathrm{K}$ \\ $\mathrm{u}_{1}, \mathrm{u}_{2} \quad$ velocity components, $\mathrm{m} / \mathrm{s}$ \\ $\mathrm{U}$ tangential fluid velocity, $\mathrm{m} / \mathrm{s}$ \\ $\mathrm{X}_{1}, \mathrm{X}_{2}$ cartesian coordinates

\section{Greek symbols} \\ $\alpha \quad$ thermal diffusivity, $\mathrm{m}^{2} / \mathrm{s}$ \\ $\beta \quad$ thermal expansion coefficient, $\mathrm{K}^{-1}$ \\ $\varphi \quad$ area fraction between the fin and the cavity \\ $\dot{\gamma} \quad$ strain rate \\ $\eta \quad$ non-Newtonian fluid viscosity, Pa.s \\ $\eta_{0} \quad$ lower apparent viscosity, Pa.s \\ $\eta_{\infty} \quad$ upper apparent viscosity, Pa.s \\ $\lambda \quad$ characteristic time, $\mathrm{s}$ \\ $\tilde{\eta} \quad$ dimensionless fluid viscosity \\ $\eta^{*} \quad$ viscosities ratio \\ $\rho \quad$ density, $\mathrm{kg} / \mathrm{m}^{3}$ \\ $\psi \quad$ Reynolds number ratio \\ $\tau_{\mathrm{ij}} \quad$ extra stress tensor, $\mathrm{N} / \mathrm{m}^{2}$

\section{Subscripts} \\ $\mathrm{i}, \mathrm{j} \quad$ vector components \\ $\mathrm{H}$ index relative to the cavity height \\ $\infty \quad$ free stream
}




\section{INTRODUCTION}

A wide variety of fluids for industrial applications have a non-Newtonian behavior. Examples include fused polymers, food products such as jellies, sauces, dairy products, biological fluids such as blood and lymph, fused rubbers, cosmetics such as creams, gels and pastes (Barnes, 2000). Currently, special attention has been giving to paraffin oils that deposit inside the oil extraction ducts and may cause them clogging, damaging the operation of systems (Wardhaughn, 1991).

For purely viscous non-Newtonian fluids the relationship between stress and strain rate is not linear (Bird et al., 1987). Therefore, the viscosity is not a single parameter in the definition of the rheological behavior of the material. Among the different known and classified non-Newtonian behaviors, pseudoplasticity is the phenomenon of viscosity reduction with increasing strain rate. It can be said that this is one of the most common nonNewtonian behaviors that most affect industrial processes. Understanding the processes of heat convection in non-Newtonian fluids is of great importance, because they have different characteristics of the processes with Newtonian fluids.

For Newtonian fluids, mixed convection from a fin introduced into a cavity was investigated in the work of Shi and Oztop et al. (2009). This paper aims to understanding and quantifying mixed convection for different fin geometries or obstacles introduced into the cavity. The works of Dos Santos et al. (2013) and Lorenzini et al. (2016) were the pioneers to use the Constructal Design to analyze the effects of cavity and fin geometry on heat transfer performance.

The Construtal Law was declared by Professor Adrian Bejan in 1997 and states that "for a finite-size system to persist in time, it must evolve in such a way that it provides easier access to the imposed currents that flow through it” (Bejan, 2000; Bejan et al., 2008 and Bejan, 2016). The Constructal Design happens spontaneously in nature (Bejan et al., 2012; Bejan, 2016), and explains similar geometries found for different systems where there is flow, such as the delta of a river and the human lung. When applied to engineering systems, in the form of the Construtal Design method, the degrees of freedom of the systems, subject to constraints, can be modified to obtain optimized geometries.

Recently, the Constructal Design method has been used in the analysis of thermal systems with non-Newtonian fluids. Klein et al., (2017a), have developed a non-Newtonian version of the Bejan number, which is a dimensionless pressure drop parameter usually employed in the Constructal Design of tubes bundles. Klein et al., (2017b) have applied the Constructal Design and the nonNewtonian number of Bejan to optimize the shape of a line of elliptical tubes subjected to the cross-flow of pseudoplastic fluids. They employed the aspect ratio of the ellipse and the distance between the tubes as design parameters and the heat transfer density as the objective function to be maximized. They also explored the effects of fluid rheology on the optimal geometries obtained.

In another study, Klein et al. (2018) investigated the effects of the Bejan and Prandtl numbers on the optimal geometries obtained through the Constructal Design. Hermany et al., (2018) used the Constructal Design to analyze the effect of rheological parameters on the forced convection of viscoplastic fluids in cross flow on a line of elliptical tubes. Sehn et al., (2017) employed the Constructal Design to investigate the best $\mathrm{Y}$-shaped flow bifurcations while Pepe et al. (2017a) investigated T-shaped bifurcations, showing that non-Newtonian fluids affect the optimal forms for these structures and that the Hess-Murray law loses its validity for nonNewtonian fluids (Pepe et al., 2017b).

In this work, the Construtal Design method is used to find the optimal ratio between height and length for a fin inserted in a cooled square cavity by non-Newtonian fluids, and to analyze the effect of fluid dynamics and rheological parameters in the form of optimized geometry and in the maximum heat transfer rate.

\section{METHODOLOGY}

The problem investigated consist of a mixed convection inside a cavity with a fin inserted in its bottom and can be represented in a two-dimensional domain, since the case does not consider fields as a function of the direction perpendicular to the cavity cut plane. The mathematical modeling of the problem is based on the computational domain shown in Fig. 1. Here, $\mathrm{H}$ and $\mathrm{L}$ represents the cavity height and width, and $\mathrm{H}_{1}$ and $\mathrm{L}_{1}$ are the fin height and width.

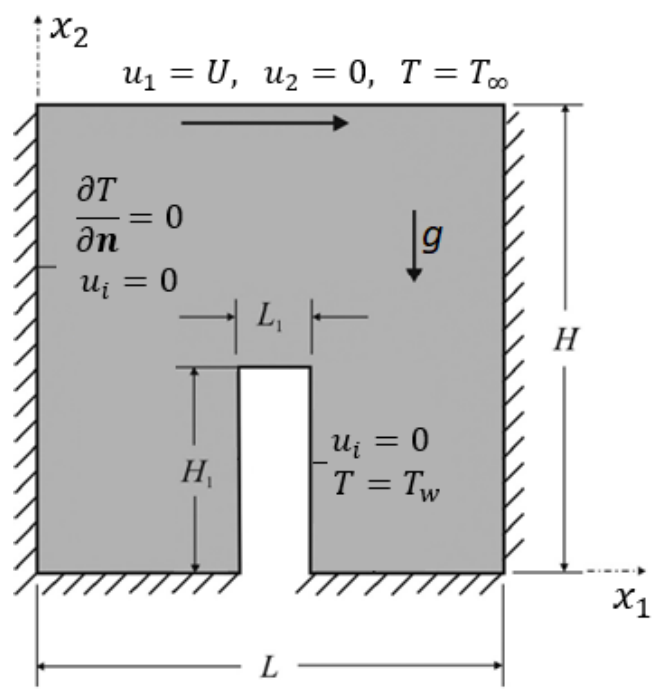

Figure 1. Problem's domain and boundary conditions adapted from Lorenzini et al., (2016). 
The cavity is filled with a fluid. The boundary conditions of the domain are impermeable walls, nonslip and adiabatic, with a prescribed temperature in the cavity walls, equal to $T_{w}$. At the top of the domain, are imposed a tangential velocity equal to $U$ and a temperature equal to $\mathrm{T}_{\infty}$.

The characteristic length for this problem is considered as the fin height, $\mathrm{H}$. It was investigated the fin aspect ratios $\mathrm{H}_{1} / \mathrm{L}_{1}$, which result in the highest heat transfer rates.

From the constructal principle, it's considered that the systems have physical limitations, therefore their dimensions must be finite. Thus, it's considered that the fraction of area occupied by the cavity is a constraint of the problem, and that the objective function for the fin's shape optimization problem is the Nusselt number, which quantifies the heat transfer from the fin. The Nusselt number for this problem is calculated as:

$$
N u_{H}=\frac{q H}{\left(2 H_{1}+L_{1}\right) k\left(T_{w}-T_{\infty}\right)}
$$

\section{MATHEMATICAL MODEL}

The mathematical model of this problem consists of the equations of mass, momentum and energy balances for a generalized Newtonian liquid (GNL) with constant properties (Bird et al., 1987).

$$
\begin{gathered}
\frac{\partial u_{i}}{\partial x_{i}}=0 \\
\rho u_{i} \frac{\partial u_{i}}{\partial x_{i}}+\frac{\partial p}{\partial x_{i}}-\frac{\partial \tau_{i j}}{\partial x_{i}}+\rho g_{i} \beta\left(T-T_{\infty}\right)=0 \\
u_{i} \frac{\partial T}{\partial x_{i}}-\frac{1}{\alpha} \frac{\partial^{2} T}{\partial x_{i} \partial x_{i}}=0
\end{gathered}
$$

where $\mathrm{u}_{\mathrm{i}}$ are the velocity vector components, $\mathrm{p}$ is the pressure field, $\mathrm{x}_{\mathrm{i}}$ is the position vector components, $\tau_{\mathrm{ij}}$ is the components of the extra stress tensor, $\rho$ is the density, $g_{\mathrm{i}}$ is the gravity vector components, $\beta$ is the thermal expansion coefficient, $\alpha$ is the thermal diffusivity. Furthermore, a constitutive equation for $\tau_{\mathrm{ij}}$ is used. For a generalized Newtonian fluid, the extra stress tensor is defined by:

$$
\tau_{i j}=\eta D_{i j}
$$

where $\eta$ is the viscosity function and $D_{i j}$ is the strain rate tensor.

In the present work, the viscosity function models the pseudoplastic behavior of the fluids for which the viscosity decreases with increasing strain rate. The Carreau model is used, which is very similar to the Power Law Model (Chhabra et al., 2008). This model describes the viscosity behavior at low, medium and high shear rates, in a single equation, given by:

$$
\eta(\dot{\gamma})=\eta_{\infty}+\left(\eta_{0}-\eta_{\infty}\right)\left(1+(\lambda \dot{\gamma})^{a}\right)^{\frac{n-1}{a}}
$$

where $\eta_{0}$ is the lower apparent viscosity, $\eta_{\infty}$ is the upper apparent viscosity, $\lambda$ is the characteristic time, $\mathrm{n}$ is the power index, and $a$ is a dimensionless parameter that describes the transition region between the low shear rate region and viscosity drop region according with the Power Law.

In the present paper, the Carreau model is employed using the parameter $a$ equal to 2, in the dimensionless form:

$$
\tilde{\eta}=\eta^{*}+\left(1-\eta^{*}\right)\left(1+\left(\dot{\gamma}^{*}\right)^{a}\right)^{\frac{n-1}{a}}
$$

where

$$
\tilde{\eta}=\frac{\eta}{\eta_{0}} ; \eta^{*}=\frac{\eta_{\infty}}{\eta_{0}} ; \dot{\gamma}^{*}=\frac{\dot{\gamma}}{\lambda}
$$

Thus, it is possible to study the effect of nondimensional rheological parameters using this model. These parameters are the viscosities ratio $\eta^{*}$ the flow index, $\eta$, and a parameter as a function of characteristic time of the model. In the present paper is used the rheological Reynolds number, $\mathrm{Re}_{\mathrm{r}}$ (Souza Mendes, 2007):

$$
\operatorname{Re}_{r}=\frac{\rho L^{2}}{\lambda \eta_{0}}
$$

The physical meaning of rheological Reynolds number is a ratio between the flow inertia and the fluid viscosity. Thus, the dimensionless parameters that characterize the investigated problem in this work are: the Reynolds number, the Prandtl number, the Rayleigh number, the ratio between the Reynolds number and the rheological Reynolds number, the flow index and the viscosities ratio. They are defined as:

$$
\begin{gathered}
\operatorname{Re}_{H}=\frac{\rho U_{\infty} H}{\eta_{0}} \\
\operatorname{Pr}=\frac{\eta_{0}}{\rho \alpha}
\end{gathered}
$$




$$
\begin{gathered}
\mathrm{R} a_{H}=\frac{g \beta \rho\left(T_{w}-T_{\infty}\right) H^{3}}{\eta_{0} \alpha} \\
\psi=\frac{\operatorname{Re}_{H}}{\operatorname{Re}_{r}}
\end{gathered}
$$

\section{CONSTRUCTAL DESIGN METHOD}

The Constructal Design method is used in the search for configurations that facilitate the access of the currents that flow through the flow systems. Identify the currents and give them freedom to flow more easily, subject to local or global constants, is the essence of the Constructal Design. The Fig. 2. Shows this method applied to the objectives of this work.

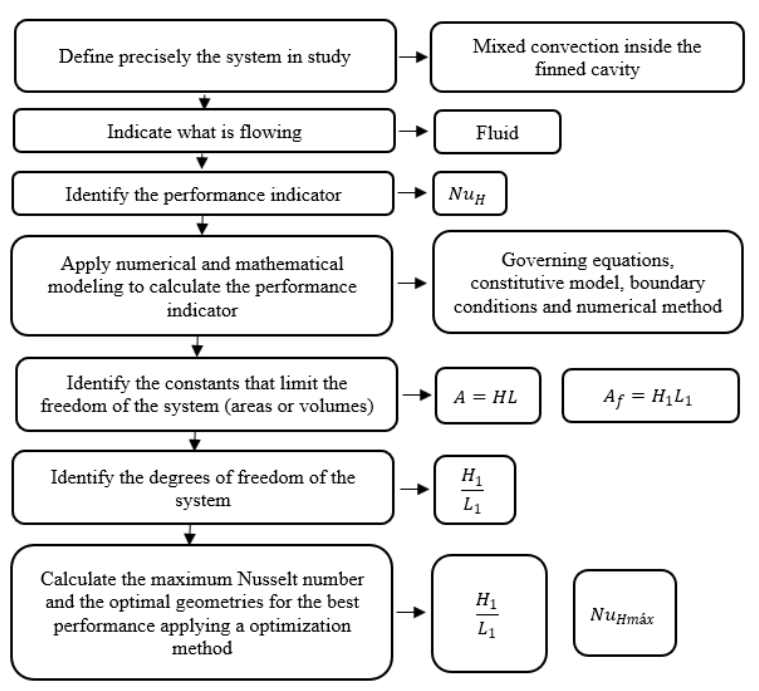

Figure 2. Implementation flowchart of the Constructal Design method.

The purpose is to maximize the Nusselt number, $N u_{H}$ using $\mathrm{H}_{1} / \mathrm{L}_{1}$ as a design variable, applying the restrictions for the variables $\mathrm{H}_{1}<\mathrm{H}$ and $\mathrm{L}_{1}<\mathrm{L}$. The cavity aspect ratio, $\mathrm{H} / \mathrm{L}$, and the area fraction occupied by the fin in the cavity's interior are keeping constant, $\varphi=\left(\mathrm{H}_{1} \mathrm{~L}_{1}\right) /(\mathrm{HL})=0.05$.

\section{NUMERICAL METHOD}

The analysis was performed using the CFD (Computational Fluid Dynamics) code ANSYS/ FLUENT v. 18.2, which is based on a finite volume method (Patankar, 1980). The Design of Experiments (DOE) ANSYS DesignXplorer was used to construct the simulations space to analyze the effect of the $\mathrm{H}_{1} / \mathrm{L}_{1}$ aspect ratio on the Nusselt number.

\section{RESULTS AND DISCUSSION}

In order to evaluate the quality of the mesh used in the simulations The GCI (Grid Convergence Index) Celik et al., 2008, was applied. Three meshes were constructed, with 61615, 38116 and 29202 finite quadrilateral volumes. Newtonian fluid case was tested with Reynolds number equal to $10^{3}$, Prandtl number was 0.71 and Rayleigh number equal to $10^{6}$. The Nusselt number was the parameter used to evaluate the quality of the meshes. The GCI of the mesh with 38116 elements was $0.13 \%$. This was the number of elements applied in the simulations for all investigated parameters range.

The first result consists of the verification of the numerical model. These results were compared with the ones published by Lorenzini et al., (2016). The Fig. 3. shows the verification of the Newtonian case with Reynolds and Rayleigh number equal to $10^{3}$. The result curves of the present work are the results obtained by the optimization tool Design of Experiments and the results obtained using 10 aspect ratios equally spaced. It was observed an excellent agreement between the results.

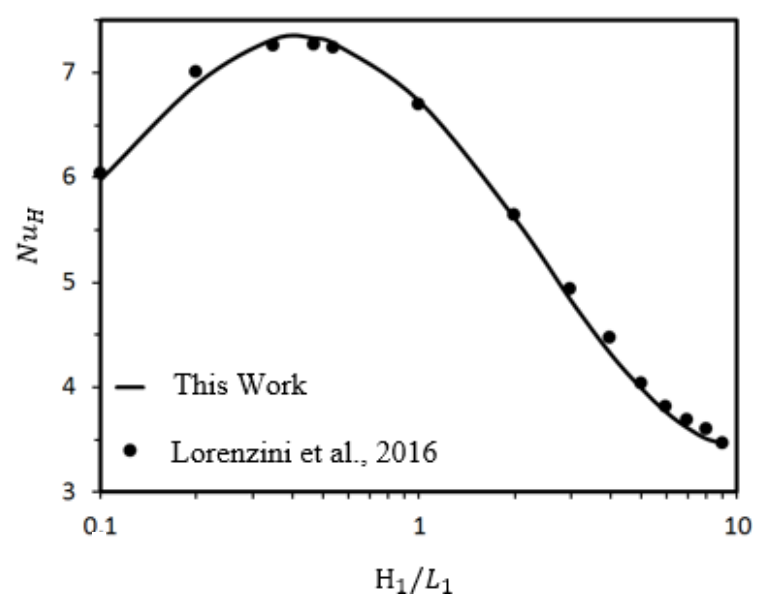

Figure 3. Results comparison of this work with the results of Lorenzini et al. (2016), for a Newtonian fluid, $\mathrm{Re}=10^{3}, \mathrm{Ra}=10^{3}$.

The second group of results consists of the sensitivity analysis of the dimensionless parameters which influence the heat transfer from the fin. They are: the Reynolds number, the Prandtl number, the Rayleigh number, the ratio between the Reynolds number and the rheological Reynolds number, the flow index and the viscosity ratio. These parameters were used in several combinations, as shown in Fig. 4. It was evaluated for which combinations of parameters the variation of $\mathrm{H}_{1} / \mathrm{L}_{1}$ could result in considerable increases in the Nusselt number. It was verified for the combination of low Reynolds and Rayleigh numbers, that the variation of the $\mathrm{H}_{1} / \mathrm{L}_{1}$ aspect ratio did not result in considerable $\mathrm{Nu}_{\mathrm{H}}$ increases. Thus, the influence of rheological parameters $\eta^{*}, \psi$ and $n$ on the values of nusselt number and optimal geometries was investigated. 


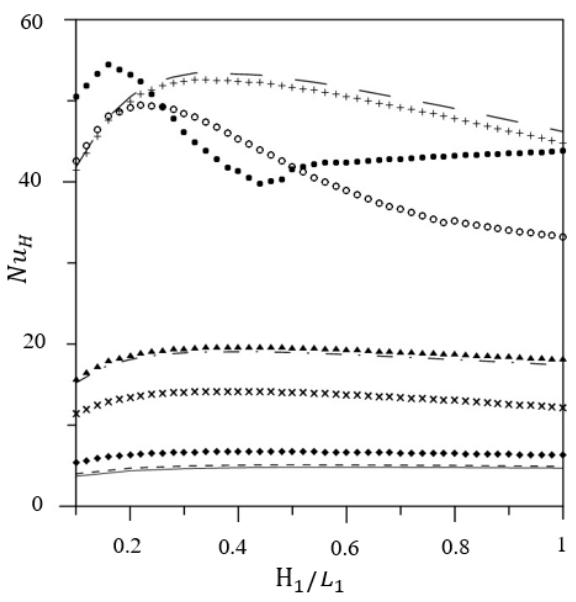

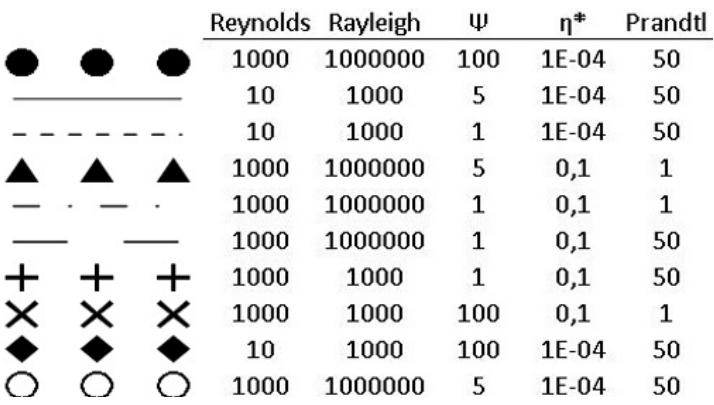

Figure 4. Sensitivity analysis of flow parameters in the optimization of the $\mathrm{H}_{1} / \mathrm{L}_{1}$ aspect ratio.

The parameters variation were done on a base case in which $\operatorname{Re}=500, \operatorname{Pr}=50, \operatorname{Ra}=10^{6}, n=0.4$, $\eta^{*}=10^{-4}$ and $\psi=100$. In this base case, in each analysis was varied only the investigated parameter.

The first parameter investigated was the ratio between the Reynolds number and the Rheological Reynolds number, $\psi$. Three values of $\psi: 1,5$ and 100 were investigated, and the results are shown in Fig. 5(a). It is verified that the higher values of $\psi$ resulted in higher $\mathrm{Nu}_{\mathrm{H}}$ value. This is because $\psi$ represents the forced flow intensity, so higher values of this parameter promote higher heat transfer. It was also detected that, for higher $\psi$, the optimal $\mathrm{H}_{1} / \mathrm{L}_{1}$ ratio is lower. Only for high values of $\psi$ a minimum value of $\mathrm{Nu}_{\mathrm{H}}$ is observed. This effect occurs only when the non-Newtonian behavior of the fluid is very pronounced, and is not present, e.g. in the results of Lorenzini et al., (2016) for Newtonian fluids.

In Fig. 5(b)., it is observed the effect of the viscosity ratio, $\eta^{*}$, while Fig. 5(c). shows the effect of the flow index, $n$. The lower the $\eta^{*}$ ratio, the higher the viscosity drop when the strain rate increases. However, it is observed that when $\eta^{*}$ goes from $10^{-1}$ to $10^{-2}$ the $\mathrm{Nu}_{\mathrm{H}}$ has an increase, but with greater reduction of $\eta^{*}$ the $\mathrm{Nu}_{\mathrm{H}}$ decreases. For the flow index, $n$, it is verified that the more pseudoplastic the fluid is, i.e. the smaller the value of $n$, the higher the $\mathrm{Nu}_{\mathrm{H}}$ value due to the reduction of the non-Newtonian viscosity with the strain rate increases.

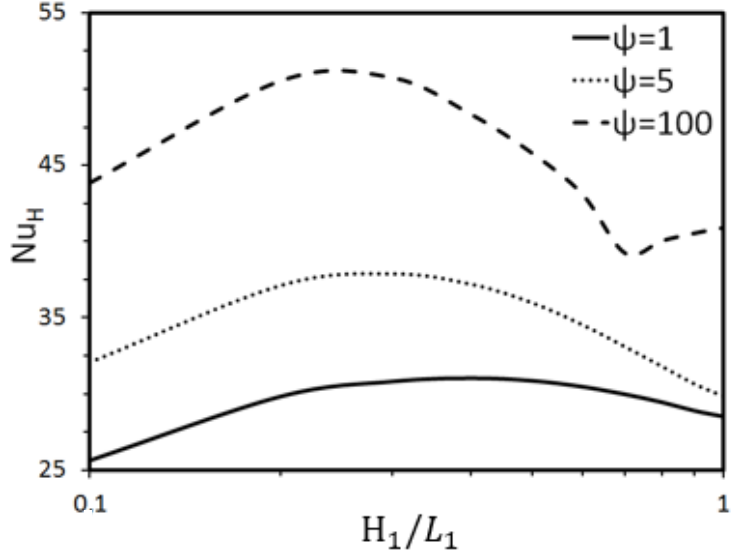

(a)

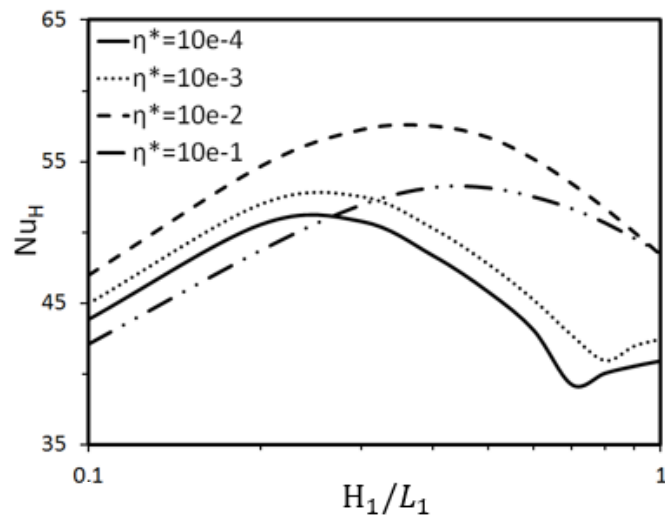

(b)

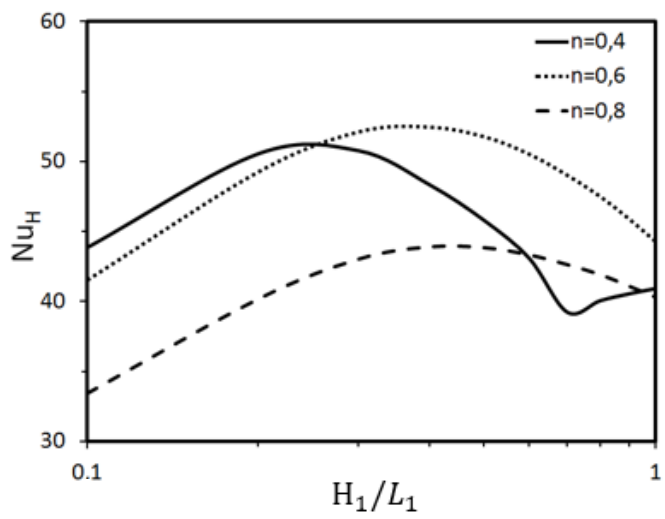

(c)

Figure 5. Effect of rheological parameters on the Nusselt number. (a) $\psi$, (b) $\eta^{*}$ and (c) $n$.

\section{CONCLUSIONS}

In this work, the Constructal Design for a fin inserted in a square cavity subjected to mixed convection from non-Newtonian pseudoplastic fluids was investigated. It was observed that, according to previous works, e.g. (Lorenzini et al., 2016), the variation of the fin aspect ratio has an important effect on the heat transfer increase only to high values of Reynolds and Rayleigh numbers.

The effects of rheological parameters were investigated, such as the ratio between the Reynolds number and the rheological Reynolds number, 
viscosity ratio and flow index on the fin heat transfer and the effect of the fin aspect ratio on the heat transfer rate, keeping the parameters $\operatorname{Re}=500, \operatorname{Pr}=50$ and $\mathrm{Ra}=10^{6}$ fixed.

It was elaborated a base case with parameters $\mathrm{Re}=500, \operatorname{Pr}=50, \mathrm{Ra}=10^{6}, n=0.4, \eta^{*}=10^{-4}$ and $\psi=100$. From this case, the rheological parameters $\eta^{*}, \psi$ and $n$ were varied. It was observed that the rheological parameters influence not only the heat transfer rates but also the optimal configurations according to the Constructal Design method.

Therefore, the results of this work suggest the creation of specific designs for non-Newtonian fluid applications in order to always work with configurations that have better performance.

\section{ACKNOWLEDGEMENTS}

The authors acknowledge with gratitude the CNPq for the Productivity and Research grants, given to Prof. Luiz Alberto Oliveira Rocha and the Scientific Initiation grant given to student Tiago Armando Hirt.

\section{REFERENCES}

Barnes, H. A., 2000, A Handbook of Elemental Rheology, Published by the University of Wales Institute of Non-Newtonian Fluid, Cambrian Printers.

Bejan, A., 1997, Constructal-Theory Network of Conducting Paths for Cooling a Heat Generating Volume, International Journal of Heat and Mass Transfer, Vol. 40, No. 4, pp. 799-816.

Bejan, A., 2000, Shape and Structure, from Engineering to Nature, Cambridge University Press.

Bejan, A., and Lorente, S., 2008, Design with Constructal Theory, Wiley, Hoboken, NJ.

Bejan, A., and Zane, J. P., 2012, Design in Nature: how the Constructal Law Governs Evolution in Physics, Biology, Technology, and Social Organization, U.S.A.

Bejan, A., 2016, The Physics of Life, St. Martin’s Press, U.S.A.

Bird, R. B., Armstrong, R. C., and Hassager, O., 1987, Dynamics of Polymeric Liquids, John Wiley \& Sons.

Celik, I. B., Ghia, U., Roache, P., J., Freitas, C., J., Coleman, H., and Raad, P., E., 2008, Procedure for Estimation and Reporting of Uncertainty Due to Discretization in CFD Applications, Journal of Fluids Engineering, Vol. 130, No. 7, pp. 4.

Chhabra, R. P., Richardson, J. F., 2008, NonNewtonian Flow and Applied Rheology- Engineering Applications, BH Printer.

Dos Santos, E. D., Isoldi, L. A., Souza, J. A., Goulart, M. M., Rodrigues, M. K., Seibt, F. M., and Rocha, L. A. O., 2013, Constructal Design of a Rectangular Fin Intruded into Forced Convective Lid-Driven Cavity Flows, Proceedings of
Construction Law Conference, Nanjing, Vol. 43, No. 5-6, pp. 126-134.

Hermany, L., Zinani, F. F., and Rocha, L. A. O., 2018, Constructal Design of the Shape of Elliptic Tubes in Forced Convection of Viscoplastic Fluids: Effects of Prandtl Number, in: VIII Brazilian Conference on Rheology - BCR, São Leopoldo, Brazil, Vol. 93, pp. 23-26.

Klein, R. J., Biserni, C., Zinani, F. S. F., and Rocha, L. A. O., 2017a, Constructal Design of Tube Arrangements for Heat Transfer to Non-Newtonian Fluids, International Journal of Mechanical Sciences, Vol. 133, pp. 590-597.

Klein, R. J., Lorenzini, G., Zinani, F. S. F., and Rocha, L. A. O, 2017b, Dimensionless Pressure Drop Number for Non-Newtonian Fluids Applied to Constructal Design of Heat Exchangers, International Journal of Heat and Mass Transfer, Vol. 115, pp. 910-914.

Klein, R. J., Zinani, F. S. F., Rocha, L. A. O., and Biserni, C., 2018, Effect of Bejan and Prandtl Numbers on the Design of tube Arrangements in Forced Convection of Shear Thinning Fluids: a Numerical Approach Motivated by Constructal Theory, International Communications in Heat and Mass Transfer, Vol. 93, pp. 74-82.

Lorenzini, G., Machado, B. S., Isoldi, L. A., dos Santos, E. D., and Rocha L. A. O., 2016, Constructal Design of Rectangular Fin Intruded into Mixed Convective Lid-Driven Cavity Flows, International Journal of Heat and Mass Transfer, Vol. 138, No. 56, pp. 418-440.

Mendu, S. S., and Das, P. K., 2012, Flow of Power-Law Fluids in a Cavity Driven by the Motion of Two Facing Lids - A Simulation by Lattice Boltzmann Method, Journal of Non-Newtonian Fluid Mechanics, Vol. 175-176, pp. 10-24.

Oztop, H. F., Zhao, Z., and Yu, B., 2009, Conduction-Combined Forced and Natural Convection in Lid-Driven Enclosures Divided by a Vertical Solid Partition, International Communications in Heat and Mass Transfer, Vol. 36, No. 7, pp. 661-668.

Patankar, S. V., 1980, Numerical Heat Transfer and Fluid Flow, McGraw-Hill.

Pepe, V., R., Rocha, L. A. O., and Miguel, A. F., 2017, Optimal Branching Structure of Fluidic Networks with Permeable Walls, Biomed Research International.

Pepe, V., R., Rocha, L. A. O., and Miguel, A. F., 2017, Is it the Hess-Murray Law always Valid?, The Publishing House of the Romanian Academy.

Rocha, L. A. O., Lorente, S., and Bejan, A. (Eds.), 2013, Constructal Law and the Unifying Principle of Design (Understanding Complex Systems), Springer.

Sehn, A., Pepe, V. R., Zinani, F. S. F, Rocha, L. A. O., and Miguel, A. F., 2017, Numerical Study of Non-Newtonian Fluid Flows in Y-Shaped Structures, in: XXXVIII Ibero-Latin American Congress on 
Computational Methods in Engineering, Florianópolis, Santa Catarina - CILAMCE, 12 pp.

Souza Mendes, P. R., 2007, Dimensionless Non-Newtonian Fluid Mechanics, Journal of NonNewtonian Fluid Mechanics, Vol. 147, pp. 109-116.

Sousa, R. G., Poople, R. J., Afonso, A. M., Pinho, F. T, Oliveira, P. J., Morozov, A., and Alves, M. A., 2016, Lid-Driven Cavity Flow of Viscoelastic Liquids, Journal of Non-Newtonian Fluid Mechanics, Vol. 234, pp.129-138.

Syrakos, A., Geourgiou, G. C., and Alexandrou, A. N., 2014, Performance of the Finite Method in Solving Regularised Bingham Flows: Inertia Effects in the Lid-Driven Cavity Flow, Journal of NonNewtonian Fluid Mechanics, Vol. 208-209, pp. 88107.

Syrakos, A., Geourgiou, G. C., and Alexandrou, A. N., 2013, Solution of the Square Lid-Driven Cavity Flow of a Bingham Plastic Using the Volume Method, Journal of Non-Newtonian Fluid Mechanics, Vol. 195, pp. 19-31.

Wardhaugh, L. T., and Boger, D. V., 1991, Flow Characteristics of Waxy Crude Oils: Application to Pipeline Design, American Institute of Chemical Engineers Journal, Vol. 37, pp. 871-885.

Zhang, J., 2010, An Augmented Lagrangian Approach to Binghan Fluid Flows in a Lid-Driven Square with Piecewise Linear Equal-Order Finite Elements, Computer Methods in Applied Mechanics and Engineering, Vol. 199, pp. 45-48. 